Article Type: Original Article

\title{
REASONS WOMEN DO NOT SEEK HEALTH CARE FOR DYSMENORRHEA
}

\section{Authors:}

1. Chen X. Chen, PhD, RN (corresponding author), Indiana University School of Nursing

Mailing address: 600 Barnhill Drive, Nursing 414, Indianapolis, IN, 46202

Telephone: +1 (317) 274 -7441 Email: cxchen@iu.edu

2. Carol Shieh, DNSc, MPH, RNC-OB, Indiana University School of Nursing

Mailing address: 600 Barnhill Drive, Nursing E413, Indianapolis, IN, 46202

Telephone: +1 (317) 278-1575 Email: wshieh@iu.edu

3. Claire B. Draucker, PhD, RN, APRN, FAAN, Indiana University School of Nursing

Mailing address: 600 Barnhill Drive, Nursing W409, Indianapolis, IN, 46202

Telephone: +1 (317) 274-4139Ｅmail: cdraucke@iu.edu

4. Janet S. Carpenter, PhD, RN, FAAN, Indiana University School of Nursing

Mailing address: 600 Barnhill Drive, Nursing 414, Indianapolis, IN, 46202

Telephone: +1 (317) 278-6093 Email: carpentj@iu.edu

Acknowledgements: The authors thank Drs. Kristine Kwekkeboom and Sandra Ward for their insights into the parent study, and Ms. Angela Beeler for careful edits of this paper. Our appreciation also goes to the women who participated in this study.

Funding: The first author was supported by Grant Number 5T32 NR007066 from the National Institute of Nursing Research of the National Institutes of Health during preparation of this paper. The content is solely the responsibility of the authors and does not necessarily

This is the author's manuscript of the article published in final edited form as:

Chen, C. X., Shieh, C., Draucker, C. B. and Carpenter, J. S. (2017), Reasons women do not seek health care for dysmenorrhea. J Clin Nurs. Accepted Author Manuscript. http://dx.doi.org/10.1111/jocn.13946 
represent the official views of the National Institutes of Health. The parent study was supported by the Eckburg Fund from the University of Wisconsin-Madison.

\section{REASONS WOMEN DO NOT SEEK HEALTH CARE FOR}

\section{DYSMENORRHEA}

\section{ABSTRACT}

Aims and objectives: The purpose of this study was to identify and describe reasons women do not seek health care for dysmenorrhea symptoms.

Background: Although dysmenorrhea is highly prevalent among women, can cause significant disruptions in their daily lives, and may increase their risk for future chronic pain conditions, few women seek health care for dysmenorrhea. A better understanding of why women do not seek health care is necessary to develop strategies that facilitate care seeking and optimal symptom management.

Design: A Qualitative Descriptive design was used to guide the study and summarize text responses to an open-ended survey question.

Methods: Participants in an online survey study who had not sought health care for dysmenorrhea $(\mathrm{N}=509)$ were asked to write about their reasons for not seeking care. Data were collected in January and February 2015. Participants' text responses were analyzed using qualitative content analysis.

Results: Nine categories of reasons were identified: assuming symptoms are normal, preferring to self-manage symptoms, having limited resources, thinking providers would not offer help, being unaware of treatment options, considering symptoms to be tolerable, being wary of available treatments, feeling embarrassed or afraid to seek care, and not seeking health care generally. 
Conclusions: Findings can guide the development of strategies to promote care seeking and inform policy and clinical practice to improve dysmenorrhea management.

Relevance to clinical practice: Findings underscore the need to provide routine screening for dysmenorrhea, avoid dismissing dysmenorrhea symptoms, initiate discussions and provide education about dysmenorrhea, provide treatments options based on evidence and women's preferences, and raise public awareness of dysmenorrhea and its impact.

\section{What does this paper contribute to the wider global clinical community?}

- The finding that women with distressing dysmenorrhea symptoms do not seek health care for a wide variety of reasons suggests that all women should be screened for dysmenorrhea during preventive and routine clinical care visits.

- Clinicians need to attend to women's dysmenorrhea symptom reports and offer treatment that meets women's needs and preferences.

- There may be a need for cultural change to improve the global society's comfort levels in talking about dysmenorrhea symptoms, to improve awareness of its impact and treatment, and decrease the silent suffering of a large population of women.

Keywords: Dysmenorrhea; health care seeking behavior; women's health; pain management; qualitative research

\section{INTRODUCTION}

Although dysmenorrhea is a prevalent and at times debilitating condition among women of reproductive age, few seek health care from professional providers to manage their symptoms. Dysmenorrhea is characterized by abdominal or pelvic pain occurring just before or during menstruation (International Association for the Study of Pain (IASP) Taxonomy 
Working Group, 2011). Globally, $45 \%$ to $95 \%$ of women of reproductive age, suffer from dysmenorrhea (Iacovides, Avidon, \& Baker, 2015); this translates to more than 855 million women worldwide. (Iacovides et al., 2015; United Nations Department of Economic and Social Affairs Population Division, 2015).

Dysmenorrhea is the leading cause of school absences and lost working hours in women (Davis, Kennedy, Moore, \& Prentice, 2007; Iacovides et al., 2015). During menstruation, women with dysmenorrhea have reduced physical activity, poorer sleep quality, and lower quality of life as compared to when they are pain-free and compared to women who are pain-free during menstruation (Iacovides et al., 2015). Dysmenorrhea commonly occurs with other pain conditions such as irritable bowel syndrome, fibromyalgia, and chronic noncyclic pelvic pain and can exacerbate the symptoms associated with these conditions (Altman et al., 2006; Giamberardino, 2008) or increase the risk for developing future chronic pain conditions (Berkley, 2013; Olafsdottir, Gudjonsson, Jonsdottir, Björnsson, \& Thjodleifsson, 2012; Vincent et al., 2011).

Evidence-based treatments are available to manage dysmenorrhea symptoms. These treatments include non-steroidal anti-inflammatory drugs, hormonal contraceptives, and transcutaneous electrical nerve stimulation (Berkley, 2013; Iacovides et al., 2015). In most countries some of these treatments, such as hormonal contraceptive pills and hormonal intrauterine devices, require prescriptions from health care providers.

In addition to gaining access to prescription treatments that provide relief for women with dysmenorrhea, health care seeking for dysmenorrhea can be beneficial for two reasons. First, given the links between dysmenorrhea and other chronic pain conditions, treating dysmenorrhea early and aggressively is more important than previously recognized (Berkley 2013). Second, seeking health care may reduce diagnostic and treatment delays for women 
whose dysmenorrhea symptoms are secondary to underlying pathological conditions such as endometriosis, uterine fibroids, or pelvic inflammatory diseases.

\section{BACKGROUND}

Despite the negative impact of dysmenorrhea on women's lives, most women do not seek health care to address their condition. For example, in the United States, up to $86 \%$ of women with dysmenorrhea do not seek health care from clinicians (Banikarim, Chacko, \& Kelder, 2000; Chen, Kwekkeboom, \& Ward, 2016; O'Connell, Davis, \& Westhoff, 2006; White \& Wildman, 1986). Similar findings have been reported in studies done in recent and older studies the United Kingdom (Hewison \& van den Akker, 1996), Malaysia (Wong, 2011), Japan (Tanaka et al., 2013), Hong Kong (Chan, Yiu, Yuen, Sahota, \& Chung, 2009), Taiwan (Chiu, Wang, Hsu, \& Liu, 2013) and Nigeria (Nwankwo, Aniebue, \& Aniebue, 2010).

Limited information is available about why women do not seek health care to address their dysmenorrhea. Older studies conducted in Western countries found that women did not seek health care for dysmenorrhea because they did not consider their symptoms to be severe (Busch, Costa, Whitehead, \& Heller, 1988; Johnson, 1988; Thompson \& Gick, 2000; White \& Wildman, 1986). A more recent US study revealed that women with dysmenorrhea do not seek health care because they do not think their symptoms have major consequences, have limited knowledge about dysmenorrhea, or view dysmenorrhea symptoms as normal (Chen et al., 2016). Several studies conducted in Asia found that women do not seek health care for dysmenorrhea because they were reluctant to have gynecological exams (Tanaka et al., 2013) or were anxious about being asked embarrassing questions (Chan et al., 2009).

Most studies have failed to fully explain variance in women's dysmenorrhea health care seeking (Chen et al., 2016; White \& Wildman, 1986). For example, in one study of 383 
college students enrolled in introductory psychology classes, symptom severity accounted for only $2 \%$ of the variance in seeking medical care (White \& Wildman, 1986). Moreover, previous studies have been limited in several ways. First, in some studies women were only asked to endorse factors related to care seeking from a pre-determined list of options (Johnson, 1988; Tanaka et al., 2013) and thus other factors that might be more important to them were not uncovered. Second, because few studies obtained narrative descriptions of women's choices not to seek health care for dysmenorrhea, we have only a shallow understanding of their choices. Third, several studies used highly selective samples of primarily younger women, including adolescent or secondary school girls (Chan et al., 2009; Johnson, 1988; Wong, 2011), nursing students (Busch et al., 1988), and college students enrolled in a psychology class (Thompson \& Gick, 2000; White \& Wildman, 1986), and thus more information is needed about health care seeking among diverse groups of women with dysmenorrhea.

The purpose of this study was to identify and describe reasons why women do not seek health care for symptoms of dysmenorrhea. A diverse sample of women with dysmenorrhea who did not seek any professional treatment for it were provided an opportunity to describe their choices not to seek health care in their own words. We sought to understand women's reasons as a foundation for designing strategies to promote health care seeking, thereby leading to improved dysmenorrhea management and, in some cases, earlier diagnosis of underlying pathological conditions and attention to other pain condition that often accompany dysmenorrhea.

This article is protected by copyright. All rights reserved. 


\section{METHODS}

\section{Design}

A basic Qualitative Descriptive (QD) design as described by Sandelowski (2000) was used to guide this study. QD is a qualitative method used when researchers aim to produce a straightforward description of a particular phenomenon. The method applies low inference analyses to produce an accurate and clear summary of data related to specific practice or policy problems. Purposive sampling, moderately structured interviews or review of pertinent written material, and standard content analysis procedures are often used. This method was chosen because our intent was to produce a coherent summary in everyday language of reasons why women did not seek health care for dysmenorrhea and to present the findings in a way that would be useful to clinicians and researchers who wish to address the problem of underutilization of health care in this population.

\section{Participants and data collection}

Participants in this study $(\mathrm{N}=509)$ were drawn from a cross-sectional study of 762 women with dysmenorrhea who were recruited in January and February 2015 (called the parent study). The parent study, which has been described in detail elsewhere, focused on dysmenorrhea self-management behaviors (Chen et al., 2016).

Participants for the parent study were recruited from a database maintained by an online survey provider (Qualtrics, Provo, UT). The database consisted of a list of potential study participants who declared an interest in online survey participation. Eligibility criteria for the parent study were as follows: (1) adult women ( $\geq 18$ years old), (2) able to read and write in English, (3) living in the United States, and (4) self-identified as having experienced symptoms of dysmenorrhea in the last six months (Chen et al., 2016). For the current study, 
an additional inclusion criterion was that the women reported not having sought care specifically for dysmenorrhea from a health care provider.

The parent study protocol (protocol number: 2014-1326) was reviewed by the Health Science Institutional Review Board (IRB) at the University of Wisconsin-Madison. The IRB determined that the study qualifies as exemption research. Following the IRB approval, the online survey provider used demographic data on file to identify women who met the first three eligibility criteria and sent 30,649 study invitation emails (Chen et al., 2016). Among those invited, $1,852(6.02 \%)$ responded by clicking on a hyperlink embedded in the email that took them to an IRB approved study information page that included federally required elements of informed consent. Potential participants were informed that completion of the survey implied their consent to participate. A signed informed consent was waived by the IRB given the minimal risk and anonymous nature of the study. Among potential participants who read the consent page, $1,384(74.73 \%)$ proceeded to the screening question, which verified the fourth eligibility criteria. Among 977 women whom met the eligibility criteria of the parent study, $762(78.00 \%)$ completed the survey with valid information.

The survey included items on demographic variables and dysmenorrhea selfmanagement behaviors. A closed-ended question asked women if they had sought care specifically for dysmenorrhea from a health care provider (e.g., family doctor, gynecologist, nurse practioner, physician assistant, school nurse). The 509 women who reported "no" were taken to an open-ended question asking them to indicate why they did not seek care. Some women gave one reason for not seeking care, and others gave several reasons.

\section{Data analysis}

For the current study, the participants' text responses to the open-ended question were analyzed using qualitative content analysis (Miles, Huberman, \& Saldaña, 2013), an analytical strategy frequently used with QD methods (Sandelowski, 2000). With qualitative 
content analysis, codes are derived inductively from the data rather than from a pre-existing theory (Sandelowski 2000).

Three research team members $(\mathrm{CC}, \mathrm{JC}$, and CS) read all the responses to obtain a sense of the dataset as a whole and recorded their thoughts and impressions. Next, the first author (CC) coded the responses by assigning labels to relevant text units to capture their essential meaning. The team members met regularly to review the data and the emerging codes. When disagreements regarding how text should be coded arose, the team returned to the data and arrived at consensus through group discussion. With the aid of a content-analytic summary table, as described by Miles et al. (2013), the codes were grouped into categories that represented distinct reasons why the participants had not sought care for their dysmenorrhea. A fourth research team member (CD) with extensive qualitative research experience reviewed and verified the categories. All the authors participated in the final naming of the categories. The first author (CC) then wrote narrative descriptions of each category that were reviewed and edited by the other three authors (JC, CS, and CD).

Trustworthiness was enhanced with several strategies. First, the study team, which consisted of researchers with expertise in both women's health and qualitative research, met frequently for the purpose of peer debriefing. When disagreements about coding and categorization occurred, discussion followed until consensus was reached. Second, the qualitative methodologist (CD), who was not involved in the initial coding and categorization of the data, verified that the findings were well supported by the data. Third, the first author (CC) maintained an extensive audit trail to record all analytic and methodological decisions, which was regularly reviewed by the fourth author (JC).

This article is protected by copyright. All rights reserved. 


\section{RESULTS}

As shown in Table 1, the 509 participants were a mean age of 33.6 years old $(\mathrm{SD}=$ 6.5, Range: 18-44). Most were White/Caucasian (76.1\%) and grew up in the United States $(96.9 \%)$. About one third had a Bachelor's degree or above (35.1\%), and the majority $(84.1 \%)$ had health insurance. About one-tenth $(10.8 \%)$ had been diagnosed with conditions that could contribute to secondary dysmenorrhea (e.g., endometriosis, uterine fibroids, pelvic inflammatory disease, polycystic ovary syndrome), and more than two thirds (69.2\%) reported another chronic pain condition (e.g., lower back pain, headache, irritable bowel syndrome).

Nine categories were developed by the research team representing the following reasons for not seeking care for dysmenorrhea: (a) assuming symptoms are normal, (b) preferring to self-manage symptoms, (c) having limited resources, (d) thinking providers would not offer help, (e) being unaware of treatment options, (f) considering symptoms to be tolerable, $(\mathrm{g})$ being wary of available treatments, (h) feeling embarrassed or afraid to seek care, and (i) not seeking health care generally. Each reason is described in detail below.

\section{Assuming symptoms are normal}

One hundred eighty-three participants said that a reason they did not seek health care was that they assumed that dysmenorrhea symptoms were a normal and expected part of life for women. They described the symptoms as a "natural product of having your period," "a fact of life," "something that comes with the territory," and "not something that warrants a prescription." Many of these participants assumed their symptoms were normal because they had experienced them for so long. One participant stated, "I thought it was just a normal thing for that time of month and I've had it most of my life." Others assumed the symptoms were normal because they accompanied every period. Even women who experienced severe pain 
considered this to be normal. One participant said, "I figure it [her dysmenorrhea] is normal, although... the amount of pain I experience is not normal." Some participants assumed their symptoms were normal because other women experienced the same symptoms. One participant stated, "My friends have the same symptoms, it is normal." Several participants assumed that because dysmenorrhea symptoms are so common they are merely "part of being a woman." The belief that dysmenorrhea symptoms are normal, even if they are severe or debilitating, was reinforced by other people in the participants' lives, including health care providers. Participants had often been told that their symptoms were just something "to live with." One participant stated, "When I told my doctor [about her symptoms], she said that these symptoms were normal with my periods."

\section{Preferring to self-manage symptoms}

One hundred and fifty-five participants stated that a reason they did not seek health care was that they had chosen to manage the dysmenorrhea symptoms on their own. They preferred to use over-the-counter medications, complementary health approaches, or other coping strategies. The over-the-counter medications they used included Tylenol ${ }^{\circledR}$ (i.e. brandname drug containing acetaminophen/ paracetamol), Advil ${ }^{\circledR}$ (brand-name drug containing ibuprofen), Motrin ${ }^{\circledR}$ (brand-name drug containing ibuprofen), Midol ${ }^{\circledR}$ (brand-name drug containing acetaminophen, pamabrom, and pyrilamine), and Pamprin ${ }^{\circledR}$ (brand-name drug containing acetaminophen, pamabrom, and pyrilamine), and these medications allowed them to tolerate their symptoms without seeking care from a health care provider. Some preferred to "treat the symptoms naturally" and found relief from home remedies such as applying heating pads, drinking hot ginger tea, and resting. One participant stated, "I figure all an allopathic doctor would offer me is some kind of drug which I don't want. I treat the symptoms naturally." Many of these participants tried coping strategies of a cognitive nature 
such as trying to ignore the symptoms, "toughing it [the symptoms out]," "suffering in silence," "bearing the pain," and "downplaying the symptoms to being all in my head."

\section{Having limited resources}

Fifty-six participants said that a reason they did not seek health care for dysmenorrhea was their limited resources. Some lacked insurance and could not afford "out of pocket" expenses, whereas others had insurance with cost prohibitive co-payments. Some of these participants had to be selective when seeking health care and determined that their dysmenorrhea was "not a medical priority." A few participants did not have a regular primary care provider or gynecologist whom they could consult.

\section{Thinking providers would not offer help}

Thirty-two participants stated that a reason they did not seek health care for dysmenorrhea was that they did not think that providers would help manage their dysmenorrhea symptoms. They believed that providers were concerned only with "diseases" rather than with managing symptoms or alleviating discomfort. Several had had negative experiences with previous providers when seeking help for other medical problems, which reinforced their beliefs that providers would not be helpful in treating the dysmenorrhea.

\section{Being unaware of treatment options}

Thirty-one participants said that a reason they did not seek health care was that they were unaware that there were treatment options that could ameliorate their symptoms.

Because they considered dysmenorrhea to be "untreatable," they never considered seeking health care. One participant, for example, stated "I did not realize that there was anything that could be done to help it [her dysmenorrhea]." Other participants were not aware of the full 
spectrum of treatment options. One stated, "I don't know what can be done about it [dysmenorrhea] except taking over-the-counter pain meds [medications]."

\section{Considering symptoms to be tolerable}

Thirty participants reported a reason they did not seek health care was that they considered their dysmenorrhea symptoms to be tolerable. Some of these participants thought their symptoms were not severe or bothersome enough to warrant professional help. Others were disturbed by their symptoms but chose to tolerate them and go on with their daily lives. Some participants did not seek care since they knew their symptoms would go away when their menstrual cycle ended. Because the pain would go away "after a couple of days," they chose to bear it. Other women believed their symptoms would abate at the end of their reproductive years. Some midlife participants, therefore, did not seek care because they expected that their symptoms would only last until menopause.

\section{Being wary of available treatments}

Twenty-one participants stated that a reason they did not seek health care was that they were wary of the treatments that are available for dysmenorrhea such as prescription pain medications, birth control pills, and surgeries. A few of these participants thought birth control pills were too risky, and others thought they should avoid pain medications due to concerns about dependency and addiction. Others were convinced that these treatments would only provide temporary relief of their symptoms despite the risks. One participant stated, "Even if I was diagnosed, I assume I would only be given medication to band-aid the problem but have no real solution to fix the problem."

This article is protected by copyright. All rights reserved. 


\section{Feeling embarrassed or afraid to seek care}

Fourteen participants said that a reason they did not seek health care for dysmenorrhea was that they felt embarrased or afraid to seek care. Several of these participants were embarassed to talk about their symptoms with a provider because they feared that that provider would see them as a "whiners," would not take their symptoms seriously, or would "just laugh at" them for seeking relief from symptoms that are so common. A few were afraid they would be subjected to aversive medical procedures. One participant stated, "I was afraid I would need to get invasive or painful tests." Some were fearful that they would find out that their symptoms were the result of a serious underlying disease.

\section{Not seeking health care generally}

Eleven participants stated that a reason they did not seek health care for their dysmenorrhea was that they rarely sought care of any type regardless of their health condition. These participants did not seek care unless it was an emergency, "absolutely necessary" or if they were "dying." Some of these participants had gone many years without seeing a health care provider. One stated, "The last time I went was because I was pregnant and it still took me 7 months to finally go."

\section{DISCUSSION}

The research team analyzed the written responses of 509 women in the United States to an open-ended survey item that asked why they had not sought professional health care for dysmenorrhea using a standard content analysis procedure. Nine distinct categories of reasons for not seeking care were identified and described. 
The findings of this study confirm the quantitative findings from the structured questionnaire of the parent study, which also revealed that women do not seek care for dysmenorrhea because they view it as a normal part of life or because they lack knowledge about the condition and possible treatments (Chen et al., 2016). The findings of the study presented here are also consistent with the findings of other prior studies that revealed women do not seek health care for dysmenorrhea because they do not view their symptoms as severe or consequential (Busch et al., 1988; Chan et al., 2009; Johnson, 1988; Tanaka et al., 2013; Thompson \& Gick, 2000) or feel embarrassed or afraid to seek care (Chan et al., 2009; Tanaka et al., 2013).

The findings of the current study add to the literature in several ways. Our findings provided a broader and richer description of women's reasons for not seeking health care for dysmenorrhea than found in prior studies. For example, our findings reveal that some women believe they should endure their symptoms that are limited to the time of their menstrual cycles or will subside at the end of their reproductive years. Others believe it is up to them to bear the pain or to suffer in silence. In other words, they approach their dysmenorrhea as something to suffer through rather than something to relieve. Our findings also highlight that other people in women's lives are influential in whether they seek health care in ways other studies have not. Particularly notable was the finding that some health care providers continue to give the message to women that dysmenorrhea is a trivial health concern, and thus it is not surprising that some women would assume that seeking health care for dysmenorrhea would be pointless. Moreover, while prior research has identified primarily attitudes and beliefs that cause women not to consult with professional providers, our findings bring issues related to health care access to the forefront. Some participants did not seek health care for dysmenorrhea because they could not afford to do so for a condition that was not life threatening. Similarly, the finding that some women did not seek any health care 
services provides a reminder that seeking care for dysmenorrhea should be placed in the context of general health care seeking practices.

The study findings should be understood in the context of its limitations. First, because the data consisted of responses to an open-ended question on a web-based survey, we were unable to ask participants follow-up or clarifying questions about their health seeking decisions. Second, we inquired only as to why some women did not seek treatment without exploring why other women did. Future research should explore the decision-making processes, access issues, and treatment experiences of women who obtain health care for dysmenorrhea. Third, this study was conducted among American women in the context of the US health care system and might not be applicable to women in other countries. For example, many women in our sample used over-the-counter medications to manage their pain, but such medications may not be as readily available in other countries. Similarly, women's attitudes, beliefs, and/or health care seeking behaviors would likely be differ in the context of other cultures or other healthcare systems that have universal or low-cost health care.

\section{CONCLUSION}

Based on women's own words, we conclude that there are a wide variety of reasons why women do not seek health care for dysmenorrhea. Some of these reasons are related to women's beliefs and attitudes regarding their symptoms, whereas other reasons are related to social norms, provider attitudes, and health care access issues. Our findings suggest that a variety of strategies are needed to promote greater health care seeking among women whose dysmenorrhea detracts from their quality of life and overall well-being.

This article is protected by copyright. All rights reserved. 


\section{RELEVANCE TO CLINICAL PRACTICE}

As summarized in Figure 1, our findings have five implications for clinical practice and health care policy.

\section{Provide routine screening for dysmenorrhea}

Given that women with dysmenorrhea do not seek health care for a wide variety of reasons, all women should be screened for dysmenorrhea during preventive and routine clinical care visits. Clinicians could incorporate simple screening questions into care visits. If indicated, women should also be screened for underlying pathological conditions that might underlie the dysmenorrhea symptoms.

\section{Avoid dismissing dysmenorrhea symptoms}

Clinicians should neither dismiss women's dysmenorrhea experiences nor reinforce the misconception that "nothing can be done." Clinicians who even subtly trivialize dysmenorrhea may contribute to women's reluctance to pursue relief for their symptoms and could contribute to a general distrust of the health care system. Moreover, clinicians who underestimate the effects that dysmenorrhea may have on women's functioning and quality of life, or who are unaware of the relationships between dysmenorrhea and other pain conditions, can contribute to negative health outcomes in this population.

\section{Initiate discussions and provide education about dysmenorrhea}

Clinicians should initiate discussions about dysmenorrhea and explore the effects it has one women's everyday lives. These discussions should include inquiry about the women's beliefs and attitudes about dysmenorrhea, their current self-management strategies, 
and their preferences for treatment. In these discussions, clinicians can introduce the notion that relief of pain rather than suffering in silence might be a treatment goal.

\section{Provide treatments options based on evidence and women's preferences}

Health care providers should be prepared to provide evidence-based treatments for women with dysmenorrhea women with full consideration of their preferences and clinical profiles. Because all treatments are associated with risks and benefits, decision support strategies should be used to help women evaluate these factors. Women's chosen selfmanagement strategies, including complementary pain management approaches that bring relief, should be respected. Women with limited resources should be connected to community sources that support dysmenorrhea management (e.g., free or low-cost women's health clinics) and be introduced to treatments that are less costly (e.g., generic ibuprofen rather than higher-priced branded medications).

\section{Raise public awareness of dysmenorrhea and its impact}

Our findings suggest a need to raise awareness in the public sector about dysmenorrhea. Educating the public about dysmenorrhea may increase appreciation of the negative impact of dysmenorrhea on some women's lives, enhance knowledge regarding possible treatment options, and increase comfort level of discussing dysmenorrhea. Such public education campaigns can end the silent suffering of women with this condition.

\section{REFERENCES}

Altman, G., Cain, K. C., Motzer, S., Jarrett, M., Burr, R., \& Heitkemper, M. (2006). Increased symptoms in female IBS patients with dysmenorrhea and PMS. Gastroenterology Nursing, 29(1), 4-11. doi:Doi 10.1097/00001610-200601000-00002 
Banikarim, C., Chacko, M. R., \& Kelder, S. H. (2000). Prevalence and impact of dysmenorrhea on Hispanic female adolescents. Archives of Pediatrics and Adolescent Medicine, 154(12), 1226-1229.

Berkley, K. J. (2013). Primary dysmenorrhea: An urgent mandate. Pain: Clinical Updates, 21(3), 1-7.

Busch, C. M., Costa, P. T., Jr., Whitehead, W. E., \& Heller, B. R. (1988). Severe perimenstrual symptoms: prevalence and effects on absenteeism and health care seeking in a non-clinical sample. Women \& Health, 14(1), 59-74. doi:10.1300/J013v14n01_05

Chan, S. S. C., Yiu, K. W., Yuen, P. M., Sahota, D. S., \& Chung, T. K. H. (2009). Menstrual problems and health-seeking behaviour in Hong Kong Chinese girls. Hong Kong Medical Journal = Xianggang Yi Xue Za Zhi / Hong Kong Academy Of Medicine, $15(1), 18-23$.

Chen, C. X., Kwekkeboom, K. L., \& Ward, S. E. (2016). Beliefs about dysmenorrhea and their relationship to self-management. Research in Nursing \& Health, 39(4), 263-276. doi:10.1002/nur.21726

Chiu, M. H., Wang, H. H., Hsu, S. C., \& Liu, I. P. (2013). Dysmenorrhoea and self-care behaviours among hospital nurses: a questionnaire survey. Journal of Clinical Nursing, 22(21-22), 3130-3140. doi:10.1111/jocn.12240

Davis, L., Kennedy, S. S., Moore, J., \& Prentice, A. (2007). Oral contraceptives for pain associated with endometriosis. The Cochrane Database of Systematic Reviews(3), Cd001019. doi:10.1002/14651858.CD001019.pub2

Giamberardino, M. A. (2008). Women and visceral pain: are the reproductive organs the main protagonists? Mini-review at the occasion of the "European Week Against Pain

This article is protected by copyright. All rights reserved. 
in Women 2007". European Journal of Pain, 12(3), 257-260.

doi:10.1016/j.ejpain.2007.11.007

Hewison, A., \& van den Akker, O. B. (1996). Dysmenorrhoea, menstrual attitude and GP consultation. British Uournal of Nursing (Mark Allen Publishing), 5(8), 480-484. doi:10.12968/bjon.1996.5.8.480

Iacovides, S., Avidon, I., \& Baker, F. C. (2015). What we know about primary dysmenorrhea today: a critical review. Human Reproduction Update, 21(6), 762-778. doi:10.1093/humupd/dmv039

International Association for the Study of Pain (IASP) Taxonomy Working Group. (2011). Classification of Chronic Pain Retrieved from http://www.iasppain.org/PublicationsNews/Content.aspx?ItemNumber=1673

Johnson, J. (1988). Level of knowledge among adolescent girls regarding effective treatment for dysmenorrhea. Journal of Adolescent Health Care: Official Publication of the Society for Adolescent Medicine, 9(5), 398-402.

Miles, M. B., Huberman, A. M., \& Saldaña, J. (2013). Qualitative data analysis : a methods sourcebook (3rd ed.). Thousands Oak, CA: SAGE Publications, Inc.

Nwankwo, T. O., Aniebue, U. U., \& Aniebue, P. N. (2010). Menstrual disorders in adolescent school girls in Enugu, Nigeria. Journal of Pediatric and Adolescent Gynecology, 23(6), 358-363. doi:10.1016/j.jpag.2010.04.001

O'Connell, K., Davis, A. R., \& Westhoff, C. (2006). Self-treatment patterns among adolescent girls with dysmenorrhea. Journal of Pediatric and Adolescent Gynecology, 19(4), 285-289. doi:10.1016/j.jpag.2006.05.004

Olafsdottir, L. B., Gudjonsson, H., Jonsdottir, H. H., Björnsson, E., \& Thjodleifsson, B. (2012). Natural history of irritable bowel syndrome in women and dysmenorrhea: a 
10-year follow-up study. Gastroenterology Research and Practice, 2012, 1-7. doi:doi:10.1155/2012/534204

Sandelowski, M. (2000). Whatever happened to qualitative description? Research in Nursing \& Health, 23(4), 334-340. doi:10.1002/1098-240X(200008)23:4<334::AID-

\section{NUR9>3.0.CO;2-G}

Tanaka, E., Momoeda, M., Osuga, Y., Rossi, B., Nomoto, K., Hayakawa, M., . . Wang, E. C. (2013). Burden of menstrual symptoms in Japanese women - an analysis of medical care-seeking behavior from a survey-based study. International Journal of Women's Health, 6, 11-23. doi:10.2147/IJWH.S52429

Thompson, M. L., \& Gick, M. L. (2000). Medical care-seeking for menstrual symptoms. Journal of Psychosomatic Research, 49(2), 137-140.

United Nations Department of Economic and Social Affairs Population Division. (2015). Demographic challenges and opportunities for sustainable development planning. Retrieved from http://www.un.org/en/development/desa/population/publications/pdf/trends/Populatio n2030.pdf

Vincent, K., Warnaby, C., Stagg, C. J., Moore, J., Kennedy, S., \& Tracey, I. (2011). Dysmenorrhoea is associated with central changes in otherwise healthy women. Pain, 152(9), 1966-1975. doi:10.1016/j.pain.2011.03.029

White, P. A., \& Wildman, B. G. (1986). Factors related to medical help-seeking in women with menstrual discomfort. Behaviour Research and Therapy, 24(4), 471-474.

Wong, L. P. (2011). Premenstrual syndrome and dysmenorrhea: urban-rural and multiethnic differences in perception, impacts, and treatment seeking. Journal of Pediatric and Adolescent Gynecology, 24(5), 272-277. doi:10.1016/j.jpag.2011.03.009

This article is protected by copyright. All rights reserved. 
Table 1 Demographic and Clinical Characteristics $(\mathrm{N}=509)$

\begin{tabular}{|c|c|c|c|}
\hline & $\mathrm{n}$ & $(\%)$ & Mean (SD) \\
\hline Age (years old) & & & $33.6(6.5)$ \\
\hline Hispanic Ethnicity & 51 & $(10.0)$ & \\
\hline Race & & & \\
\hline Asian/Pacific Islander & 31 & $(6.1)$ & \\
\hline Black/African American & 68 & $(13.4)$ & \\
\hline White/Caucasian & 389 & $(76.1)$ & \\
\hline Native American & 6 & $(1.2)$ & \\
\hline Others & 3 & $(0.6)$ & \\
\hline Grew up in the United States & 493 & $(96.9)$ & \\
\hline Education & & & \\
\hline High school or below & 105 & $(20.6)$ & \\
\hline Some College or Associate Degree & 225 & $(44.2)$ & \\
\hline Bachelor's and above & 179 & $(35.2)$ & \\
\hline $\begin{array}{l}\text { Diagnosed with conditions related to } \\
\text { secondary dysmenorrhea }\end{array}$ & 55 & $(10.8)$ & \\
\hline Insured & 428 & $(84.1)$ & \\
\hline Reported another chronic pain condition & 352 & $(69.2)$ & \\
\hline
\end{tabular}

This article is protected by copyright. All rights reserved. 
Figure 1. Reasons for Not Seeking Health Care and Implications for Clinical Practice and Health Care Policy

\section{Reasons for Not Seeking Health Care}

- $\quad$ Assuming symptoms are normal

- $\quad$ Preferring to self-manage symptoms

- Having limited resources

- $\quad$ Thinking providers would not offer help

- $\quad$ Being unaware of treatment options

- $\quad$ Considering symptoms to be tolerable

- $\quad$ Being wary of available treatments

- $\quad$ Feeling embarrassed or afraid to seek care

- $\quad$ Not seeking health care generally

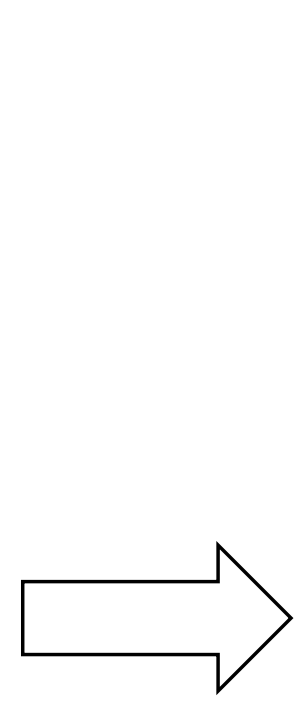

- $\quad$ Provide treatments options based on evidence and women's preferences - $\quad$ Raise public awareness of dysmenorrhea and its impact

\section{Implications}

- $\quad$ Provide routine screening for dysmenorrhea

- Avoid dismissing dysmenorrhea symptoms

- Initiate discussions and provide education about dysmenorrhea

This article is protected by copyright. All rights reserved. 